\title{
A CONSTRUÇÃO E O RECONHECIMENTO DAS REGRAS FAMILIARES: A PERSPECTIVA DOS ADOLESCENTES ${ }^{12}$
}

\author{
Paola Vargas Barbosa ${ }^{3}$ \\ Adriana Wagner \\ Universidade Federal do Rio Grande do Sul, Porto Alegre-RS, Brasil
}

\begin{abstract}
RESUMO. Os valores e regras familiares contribuem para a construção da estabilidade necessária ao desenvolvimento saudável da família e de seus membros. Para conhecer como as regras são construídas e exercidas na família realizou-se um grupo focal, durante uma hora e meia, com 15 adolescentes de 15 a 18 anos (oito meninas e sete meninos) numa escola privada do Sul do Brasil. Os dados foram transcritos e organizados por temas a partir da análise de conteúdo. Os resultados apontam que, enquanto algumas regras são prescritas pelos pais, muitas são construídas juntamente com os filhos e são adaptáveis ao contexto. Revelaram-se determinadas estratégias para a manutenção das regras. Os pais utilizam a cobrança, a punição e o controle. Por parte dos filhos, percebe-se o uso da resistência e controle de informações, criando espaço para o desenvolvimento da autonomia, enquanto buscam a manutenção do bom relacionamento parental. A conversa é relatada como a estratégia mais eficaz para manutenção das regras e se discute a importância do exercício parental na construção e manutenção das regras.
\end{abstract}

Palavras-chave: Adolescência; parentalidade; família.

\section{THE CONSTRUCTION AND RECOGNITION OF FAMILY RULES: THE ADOLESCENT'S PERSPECTIVE}

\begin{abstract}
Values and family rules contribute to the construction of the necessary stability to the healthy development of the family and its members. To know how the rules are constructed and operated in the family a focus group was held, during an hour and a half, with 15 adolescents $15-18$ years ( 8 girls, 7 boys) in a private school in southern Brazil. The group lasted one hour and a half. The results show that while some rules are prescribed by the parents, many are co-constructed and context adaptable. Certain strategies for the maintenance of rules were revealed. Parents use demand, punishment and control. The youth use strategies of resistance and information control, creating space for the development of autonomy, while seeking to maintain a good parental relationship. The conversation is reported as the most effective strategy for maintaining the rules. The importance of parental exercise in the construction and maintenance of rules is discussed.
\end{abstract}

Keywords: Adolescence, parenting, family.

\section{LA CONSTRUCCIÓN Y EL RECONOCIMIENTO DE LAS REGLAS FAMILIARES: LA PERSPECTIVA DE LOS ADOLESCENTES}

RESUMEN. Los valores y las reglas familiares contribuyen para la construcción de la estabilidad necesaria para el sano desarrollo de la familia y sus miembros. Para conocer cómo las reglas son construidas y ejercidas en la familia se realizó un grupo focal, durante una hora y media, con 15 adolescentes de 15 a 18 años (8 niñas, 7 niños) en una escuela privada en el sur de Brasil. Los datos fueron transcritos y organizados por temáticas a partir del Análisis de Contenido. Los resultados señalan que mientras algunas reglas son prescritas por los padres, muchas son co-construidas y adaptables al contexto. Se revelaron determinadas estrategias para el mantenimiento de las reglas. Los padres usan el cobro, la punición y el control. Por parte de los hijos, se percibe el uso de la resistencia y el control de informaciones, generando un espacio para el desarrollo de la autonomía, conjuntamente buscan mantener la buena relación con los

1 Este trabalho é parte da tese de doutorado da primeira autora, orientada pela segunda.

2 Apoio e financiamento: Coordenação de Aperfeiçoamento de Pessoal de Nível Superior (CAPES).

3 Endereço para correspondência: Rua Ramiro Barcelos, 2600, Instituto de Psicologia da UFRGS, sala 126, CEP 90.035-003,Porto Alegre-RS, Brasil.E-mail: paolavargasbarbosa@gmail.com. 
padres. La conversación se presenta como la estrategia más eficaz para el mantenimiento de las reglas. Se discute la importancia del ejercicio de los padres en la construcción y el mantenimiento de las reglas.

Palabras-clave: Adolescencia, parentalidad, familia.

Muitas famílias veem a adolescência como um momento de crise. A percepção culturalmente aceita de que esse é um período de não obediência às regras dos pais reforça o estereótipo do jovem como rebelde e naturaliza a dificuldade encontrada por algumas famílias em construir e manter regras. Alguns pais relatam certo estranhamento dos filhos quando chegam à adolescência. As crianças dóceis e obedientes são misteriosamente substituídas por adolescentes críticos, insatisfeitos e "construtores de suas próprias regras", como afirmam alguns responsáveis. A percepção, frequentemente equivocada, de rompimento das relações anteriormente estabelecidas entre pais e filhos torna a consolidação das regras construídas desde a infância um processo muitas vezes árduo para a família. É então de perguntar: por que pode ser difícil para algumas famílias construir e consolidar regras? Por que alguns pais têm mais sucesso do que outros nessa tarefa? Será que seguir todas as regras parentais é o ideal para o desenvolvimento dos filhos? Refletir sobre essas questões e dificuldades tem levado pesquisadores e clínicos a buscar dados que auxiliem na compreensão de como se dá o processo de construção e manutenção das regras na relação parental.

Compreende-se que as regras ou normas familiares são construídas a partir de um sistema de crenças e valores que orientam a conduta de seus membros. Esses valores são socialmente construídos, e são selecionados por serem coerentes com o contexto e a história de cada indivíduo ou família (Rodrigo \& Palacios, 2003). A partir dessa base valorativa, as famílias constroem regras explícitas ou implícitas para orientar e dar estabilidade e previsibilidade às suas relações (Livingston, 2007).

Para compreender o processo de construção e manutenção das regras na família as pesquisas tradicionais vinham focando as ações dos pais, estudando a explicitação das normas e os lembretes sobre as regras ou como aqueles garantiam o cumprimento dessas regras. Os modelos de socialização criados a partir dessas pesquisas consideravam a influência dos filhos nesse processo, mas entendiam sua atividade apenas como reativa; ou seja, entendiam que os filhos reagiriam obedecendo ou não às normas estabelecidas pelos pais (Parkin \& Kuczynski, 2012). Mais tarde essa área de pesquisa passou a compreender a bidirecionalidade da interação pais e filhos (Maccoby, 2007), aparecendo estudos mais recentes sobre o papel dos filhos como agentes do processo de socialização e construção de regras (Keijsers \& Laird, 2010; Parkin \& Kuczynski, 2012).

Nas últimas décadas algumas pesquisas vêm observando que o processo de construção e manutenção das regras tem se tornado cada vez mais flexível. Em vez de afirmar regras únicas em diferentes situações, os pais têm se mostrado mais abertos, adaptando seu comportamento e seus objetivos aos contextos em que a regra é necessária, e até mesmo ao histórico de comportamento da criança ou adolescente (Smetana, 1997). Dessa forma, observa-se que os pais acabam por comunicar aos filhos uma série de expectativas sobre seu comportamento em diferentes situações, que podem variar desde o que é ideal até o que é completamente inaceitável (Parkin \& Kuczynski, 2012). Em contrapartida, a obediência ou não a essas expectativas depende dos desejos das próprias crianças e adolescentes, da avaliação que estes fazem sobre a legitimidade de tais regras, do seu senso de justiça ou da importância dos desejos parentais (Smetana, 1997).

As mudanças sociais e econômicas vivenciadas pelas famílias no último século também retroalimentam essa flexibilização das regras. As transformações nos papéis de gênero e, consequentemente, dos papéis parentais (Wagner, Predebon, Mosman, \& Verza, 2005), o enfraquecimento da hegemonia do modelo tradicional da família nuclear patriarcal (Stengel, 2011) e outras mudanças têm transformado a forma de pensar e viver a autoridade familiar, que passa a ser dividida entre os cônjuges. Assim, o modelo hierárquico da família torna-se cada vez mais igualitário, demandando mudanças também na construção e manutenção das regras. Tantas transformações tornam 0 sistema familiar um terreno fluido no que tange à autoridade, à determinação e ao cumprimento e manutenção das regras (Romanelli, 2000). 
Além da divisão da autoridade parental entre pais e mães, a crescente democratização da autoridade (que cada vez mais é discutida com os filhos e não imposta pelos pais) torna a construção das regras um assunto de difícil conceituação. Nesse processo cada vez mais democrático, os filhos têm mais espaço para expressar suas necessidades e desejos diante das regras parentais. Essa expressão pode se dar através da discussão das normas, mas geralmente se dá por meio da desobediência. $\mathrm{Em}$ qualquer fase do desenvolvimento desobedecer às normas pode ser uma demonstração de não concordância, mas acima de tudo, de insatisfação com a falta de autonomia ou liberdade. No período da adolescência a obediência é um processo ainda mais complexo. Com a construção da identidade e o desenvolvimento da autonomia, mais intensos nessa fase, torna-se difícil alcançar o equilíbrio entre obediência e desobediência e entre dependência e autonomia.

É importante atentar para o fato de que a construção das regras é um processo contínuo, que deve se manter durante a adolescência. Este também é um momento do ciclo vital em que os pais precisam estar atentos às mudanças no desenvolvimento dos filhos, adequando (e até criando) regras ao momento que a família vivencia (Carter \& McGoldrick, 1995). Regras que até o fim da infância foram úteis e funcionais, no momento da adolescência talvez tenham que ser repensadas, renegociadas ou até extintas. De qualquer maneira, mesmo que esse seja um período de consolidação e transformação dos valores e regras construídos durante a infância, entende-se que a família continua responsável pela orientação e segurança dos filhos. Sendo assim, pais e filhos vêm usando estratégias com o objetivo de garantir a manutenção e obediência às regras $e$ ainda assim manter espaços de liberdade e autonomia.

Por um lado, as pesquisas apontam que os pais utilizam estratégias com 0 intuito de monitorar as atividades e comportamentos dos filhos e garantir o cumprimento das regras e, acima de tudo, a segurança e bem-estar da prole. Estratégias como a solicitação de informações (Aonde vão? Com quem? O que vão fazer lá?) ou o controle parental (só devem sair com a autorização dos pais, devem voltar num horário específico) já são descritas desde os anos 90 na literatura como protetivas para os jovens (Stattin \& Kerr, 2000). De fato, diversas pesquisas norte-americanas e europeias demonstraram que adolescentes pouco monitorados tendem a ser mais antissociais ou envolvidos em delinquência do que os que são monitorados pelos pais (Sampson \& Laub, 1994); além disso, apresentam maior risco de envolvimento com drogas (Flannery, Vazsonyi, Torquati, \& Fridrich, 1994) e um pior desempenho na escola (White, \& Kaufman, 1997).

Por outro lado, pesquisas atuais têm apontado que as estratégias de monitoramento são, sim, protetivas, e estão associadas a menores índices de delinquência (Kerr, Stattin \& Burke, 2010), porém não são as estratégias mais eficientes. Estudiosos têm mostrado que as informações que os pais possuem sobre as atividades ou comportamentos dos filhos são muito mais advindas do próprio adolescente do que das estratégias de monitoramento dos pais (Stattin \& Kerr, 2000), ou seja, os pais dependem da decisão dos adolescentes de informar ou esconder informações (Rote, Smetana, Campione-Barr, Villalobos, \& Tasopoulos-Chan, 2012).

Por outro lado, os adolescentes também utilizam estratégias para "alimentar" os pais com informações sobre suas ações (e consequentemente sobre a obediência ou não às regras). As chamadas estratégias de controle de informações e as estratégias de resistência são utilizadas pelos adolescentes como forma de lutar contra as regras parentais ou de controlar as informações que os pais recebem sobre seu comportamento. A resistência se refere à "capacidade interpretativa dos filhos e sua habilidade de expressar autonomia no relacionamento com os pais" (Parkin \& Kuczynski, 2012, p. 634).

As estratégias são divididas em estratégias habilidosas (ex. negociação, argumentação) e menos habilidosas (ex. recusa direta, transgressão escondida). As primeiras, apesar de serem vistas pelos pais como aversivas, indicam o engajamento dos filhos na relação através da comunicação, e por isso são compreendidas como saudáveis (Parkin \& Kuczynski, 2012). As menos habilidosas podem sem prejudiciais ao relacionamento com os pais.

As estratégias de controle de informação, paralelamente, também são divididas de acordo com grau de prejuízo ao relacionamento parental. Pesquisas com amostras norte- 
americanas (Laird \& Marrero, 2010), europeias (Stattin \& Kerr, 2000) e latino-americanas (Chile) (Cumsille, Darling \& Martínez, 2010) mapearam as estratégias do comportamento dos adolescentes e as dividiram em estratégias de abertura e estratégias de segredo.

As estratégias de abertura são aquelas em que $o$ adolescente presta livremente informações sobre si, suas atividades e pensamentos. Alguns exemplos são: revelação total (quando os jovens contam tudo sobre suas ações e atividades aos pais); e revelação quando perguntado ou evitação do assunto (Cumsille, Darling \& Martínez, 2010; Smetana, Villalobos, Tasopoulos-Chan, Gettman, \& Campione-Barr, 2009). Essas estratégias são compreendidas como menos prejudiciais, pois têm por objetivo proteger o relacionamento entre pais e filhos e ao mesmo tempo buscar espaço para a expressão da autonomia dos filhos.

Em contrapartida, as estratégias de segredo envolvem algum tipo de engano, como a revelação parcial (com a omissão de detalhes importantes) ou a mentira (Cumsille, Darling \& Martínez, 2010; Smetana et al., 2009; Rote \& Smetana, 2014). Tais estratégias tendem a ser mais prejudiciais ao relacionamento parental. Quando analisadas longitudinalmente, as estratégias de segredo parecem estar mais associadas a comportamentos delinquentes e à quebra de regras, quando comparadas a estratégias com adolescentes que utilizavam com mais frequência a abertura com os pais (Laird \& Marrero, 2010).

A utilização dessas estratégias é influenciada por diversos fatores. A qualidade da relação entre pais e filhos já foi apontada como relevante. Uma ligação emocional consistente e flexível entre pais e filhos tende a impedir de que o adolescente faça algo que possa colocar em risco essa relação. Isso se refere tanto a um menor indice de envolvimento em comportamentos ilícitos quanto a uma maior revelação das ações e menos segredos com os pais (Stattin \& Kerr, 2000; Rote et al., 2012). O domínio do comportamento também é levado em conta para a decisão de usar estratégias de controle de informação. Os jovens se sentem mais obrigados a revelar ações que se referem ao domínio prudencial (ligado à segurança do adolescente) e menos obrigados a revelar comportamentos que consideram de fórum íntimo, o chamado domínio pessoal (Rote \& Smetana, 2014). Finalmente, são levados em conta os aspectos práticos da situação, como as possíveis punições que enfrentarão caso sejam descobertos. O tempo disponível para planejamento pode influenciar a quebra da regra e também a utilização da estratégia de controle de informações (Darling, Cumsille, Caldwell, \& Dowdy, 2006).

Percebe-se, então, que a relação entre pais e filhos adolescentes é constantemente marcada pelo embate entre obediência e desobediência às expectativas e regras construídas. Até agora as pesquisas nessa área afirmam que um relacionamento parental marcado pelo afeto, pelo suporte para autonomia e pela comunicação clara das regras e expectativas está associado a melhores índices de desenvolvimento e ao uso de menos estratégias negativas de resistência e de controle da informação, como, por exemplo, a mentira (Parking \& Kuczynski, 2012; Rote et al., 2012). Não obstante, ainda há muito a conhecer sobre o processo de construção e manutenção das regras, especialmente no Brasil, onde poucos são os estudos que discutem especificamente tal temática.

Para explorar esse processo algumas premissas são necessárias. Compreende-se que, em sua essência, as tarefas atribuídas aos pais (como educação, orientação, transmissão de valores e regras) continuam inalteradas (Wagner, Mosman, Dell'Aglio, \& Falke, 2010). Da mesma forma, entende-se que as regras são necessárias ao bom funcionamento de qualquer grupo, inclusive o familiar. Também se afirma a necessidade de um equilíbrio entre a construção e funcionamento das regras na família e a possibilidade de desenvolvimento da autonomia do adolescente. A partir desses pressupostos, objetivou-se compreender a percepção dos filhos sobre como são construídas e mantidas as regras em suas famílias, e nesse processo, como se expressa a autonomia.

Em conformidade com a tendência atual das pesquisas na área da Psicologia do Desenvolvimento, buscou-se dar voz aos jovens adolescentes, como forma de conhecer sua opinião sobre as regras parentais, seus desejos de autonomia e seu papel protagonista na construção da homeostase familiar.

\section{MÉTODO}

Para conhecer como os adolescentes relatam perceber as regras parentais e os 
processos de autonomia construídos em suas famílias, julgou-se que a realização de um grupo focal seria mais rica do que entrevistas individuais. A possibilidade de compreender a experiência desses jovens a partir de significados intrapessoais (pensamentos, sentimentos, valores individuais) e também intragrupais (a partir da comunicação e interação dentro de um grupo) (Millward, 2006) tornou os dados mais ricos. Essa metodologia deu oportunidade de acesso a vivências e idiossincrasias de cada adolescente (e sua família), assim como a valores e representações socioculturais importantes para a construção da relação entre pais e filhos. Além disso, permitiu que esses adolescentes exercessem seu protagonismo, através de um espaço de discussão e construção de sentido.

Foi contatada uma escola privada de Ensino Fundamental e Médio na Região Metropolitana de Porto Alegre. A proposta da pesquisa foi aprovada pela coordenação e o convite para participar de um grupo de discussões foi feito aos alunos de uma turma do $2^{\circ}$ ano do Ensino Médio. Uma carta explicativa e o Termo de Consentimento Livre e Esclarecido (TCLE) foram entregues aos alunos nessa oportunidade. Na data marcada, os alunos que quiseram participar e haviam trazido o TCLE assinado por um responsável foram levados para uma sala de reuniões no espaço da escola. Os objetivos do encontro foram mais uma vez esclarecidos e os adolescentes firmaram um contrato grupal de sigilo das identidades dos participantes.

Participaram 15 adolescentes, dos quais oito eram meninas de 15 a 18 anos $(\mathrm{M}=16,2, \mathrm{dp}=$ $0,35)$. Onze dos participantes vinham de famílias intactas e quatro de famílias separadas ou reconstituídas. A maioria dos pais e mães dos jovens participantes tinham o Ensino Superior ou pós-graduação e trabalhavam como profissionais liberais (médicos, psicólogas, etc.).

O grupo se reuniu uma vez, por cerca de uma hora e meia. A questão que orientou a realização do grupo foi: "Como as regras são construídas na sua família?" A discussão foi gravada em áudio e vídeo com a autorização prévia dos participantes e as gravações foram transcritas na íntegra para posterior análise. A partir da transcrição da discussão do grupo, as falas foram organizadas por unidade temática. As unidades temáticas, por sua vez, foram reunidas em categorias (Bardin, 2002), as quais serão apresentadas e analisadas a seguir.

\section{RESULTADOS E DISCUSSÃO}

As categorias temáticas foram agrupadas conforme o esquema abaixo. Tal esquema também orientará a apresentação e discussão dos resultados. Além disso, é preciso ressaltar que, com o objetivo de preservar a identidade dos participantes, os nomes utilizados são fictícios.

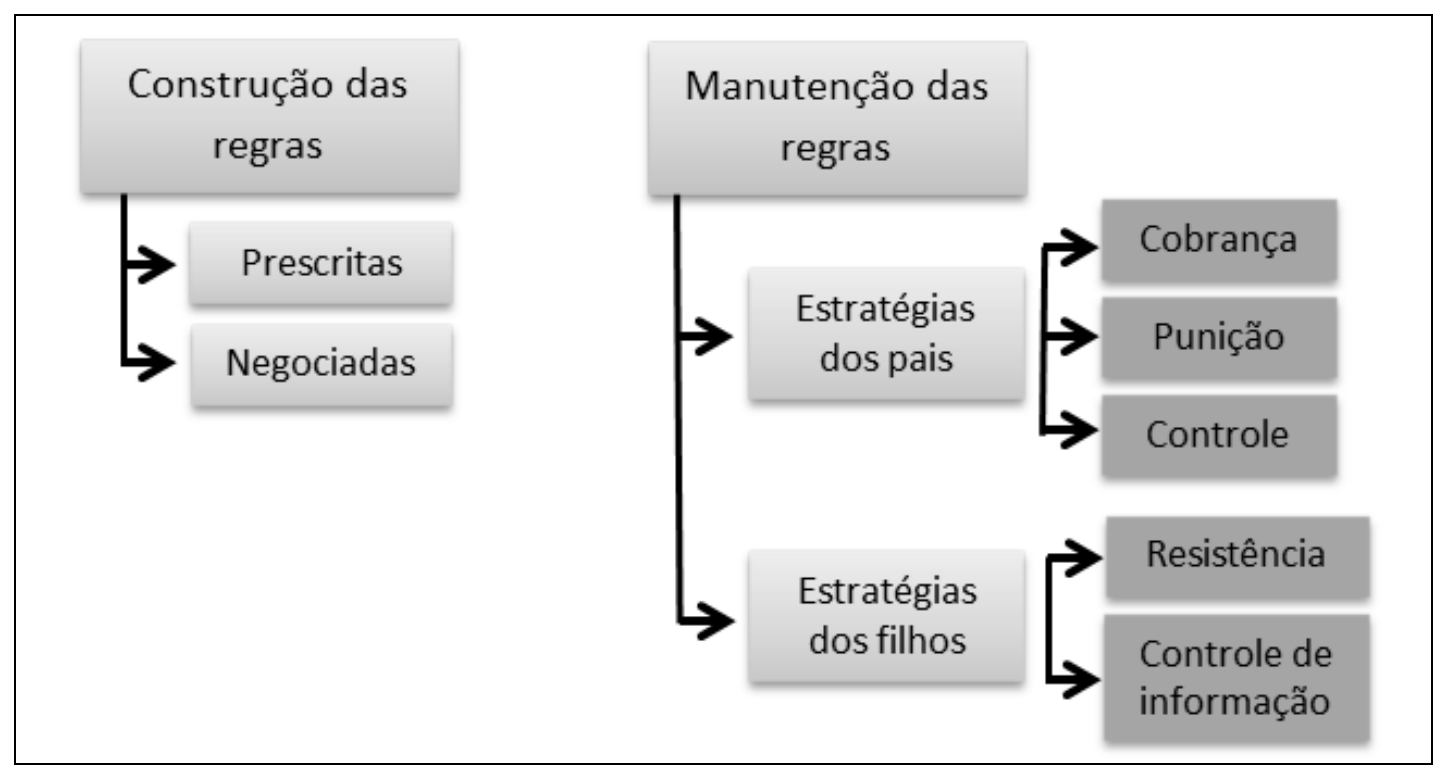

Figura 1 - Esquema das Categorias e Subcategorias Analisadas 


\section{Construção das regras}

Ao discutirem a construção de regras na família, os adolescentes relataram que não havia regras claras. Segundo a descrição dos participantes, existem expectativas implícitas e flexíveis sobre diversos temas, estabelecidas pelo bom senso dos adolescentes. Os estudos na área do desenvolvimento já apontam essa flexibilização na construção das regras, demonstrando uma maior abertura dos pais para receber as ideias e informações dos filhos para construção das normas (Parkin \& Kuczynski, 2012).

Tem algumas que podem ser discutidas, mas nem todas. Tipo, o meu pai quando ele não tá a fim de abrir um assunto pra discussão ele fala: "isso não está em discussão", daí eu tenho que fazer o que ele manda; mas, às vezes ele deixa... a gente pode chegar num consenso ou a gente pode discutir o assunto pra fazer $o$ que é melhor pra todo mundo, mas nem sempre (Celia, 16 anos).

À medida que a discussão se aprofundava, percebia-se a existência de algumas poucas regras prescritas pelos pais, referentes especialmente a assuntos de segurança (uso de drogas, saídas à noite, etc.). Um menor número de regras prescritas e a priorização de regras claras prudenciais também foram encontrados em amostras qualitativas e quantitativas em jovens estadunidenses (Parkin \& Kuczynski, 2012; Smetana, 1997).

Os adolescentes relatam a existência de regras ou expectativas relacionadas aos seguintes temas: a liberdade de sair para festas ou atividades de lazer, o rendimento escolar, a organização do quarto e pertences pessoais, a participação nas tarefas domésticas e outros. Algumas expectativas são claras, como, por exemplo, a de ter um rendimento acadêmico específico ou a necessidade de arrumar o quarto antes de fazer atividades de lazer. Outras expectativas são mais implícitas ou dependem do bom senso do adolescente:

Muitas vezes [a regra] não é do tipo: "ah, tem que fazer..." mas é tipo: "ah, poxa, né?! Ajuda!" Bom senso também... (Larissa, 16 anos). Tipo, ela deixa o lustramóveis e o perfex em cima da bancada e diz: "Ah, eu tenho que sair de casa..." e deixa ali em cima. É muito implícito, assim: limpa! Sabe? (Antônio,
16 anos). Tipo, "tu não tá fazendo nada, aí, poxa, então ajuda, né? (Larissa, 16 anos).

Além disso, outras regras parecem ser fruto de uma negociação entre pais e filhos, adaptada a um contexto e realidade específicos:

Uma coisa que foi discutida é que no fim do ano eu vou viajar, vou viajar sem eles, e isso foi discutido assim, pra ver se eu ia mesmo, pra ver como é que ia ser... e aí a gente chegou num consenso de que eu ia de fato viajar (Celia, 16 anos).

Também se pôde observar que, além da variação das regras de acordo com alguns temas, há grandes diferenças de família para família. Enquanto em algumas famílias há uma determinação mais clara de algumas regras, em outras as regras são flexibilizadas ou até mesmo invalidadas pelos adolescentes:

Não faço nada mesmo! [referindo-se a ajudar nas tarefas em casa]. E ela [a mãe] não me cobra, porque ela sabe que eu não vou fazer... (Juliana, 16 anos). Comigo também... não tem... não faço, não tem quem me faça fazer... (Vinícius, 17 anos). Não, na minha casa não é assim "não quero fazer, não vou fazer" se eles mandam, tem que fazer (Melissa, 18 anos).

De forma geral, a negociação das regras é um processo flexível, marcado pelo diálogo entre pais e filhos. Pode-se perceber que a negociação para a construção e manutenção das regras é influenciada pelo relacionamento que estabelecem entre si e pela experiência dos irmãos mais velhos e dos próprios pais. Segundo os participantes, a relação previamente estabelecida com os pais influencia a possibilidade de negociação das regras. Eles afirmam que a existência de um clima de confiança e obediência constrói espaço para barganhar e ter suas vontades atendidas:

Isso é uma coisa que se ganha com tempo, né? Se tu sempre sai e volta, sei lá, faz o que tu prometeu, começa a ganhar confiança. ... é, é isso que eu digo... é, num dia, por exemplo... ai tu vai lá e, sei lá, combina que vai ficar num lugar e fica em outro, dorme em algum outro lugar... fica difícil de conseguir as coisas depois (Fabrício, 16 anos). 
$\mathrm{Na}$ opinião de alguns dos adolescentes participantes, o processo de confiança é de idas e vindas. Quando as regras estabelecidas não são cumpridas a confiança se perde, e deverá ser reconquistada:

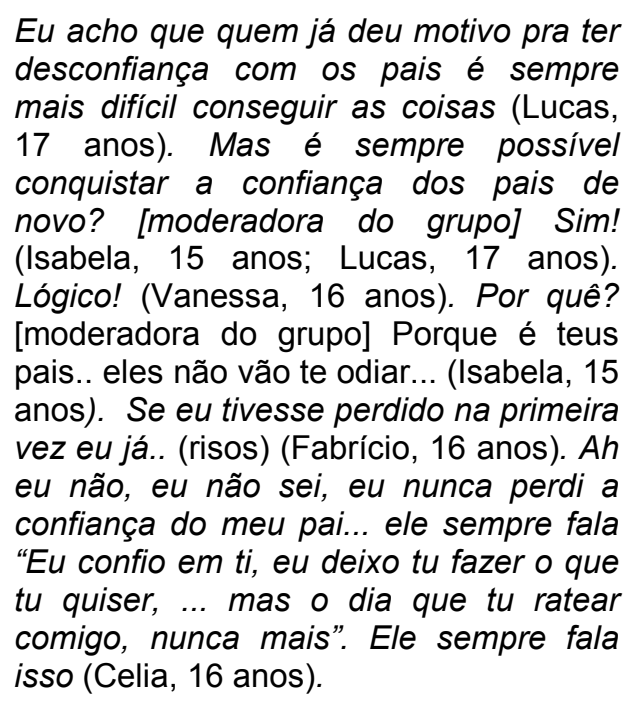

O estabelecimento das regras também é influenciado pela experiência anterior dos irmãos mais velhos e pelo exemplo dos pais. Os padrões estabelecidos para os irmãos mais velhos e os resultados anteriormente obtidos por estes orientam as expectativas impostas para os jovens:

Meu irmão mais velho normalmente ia bem [na escola], então eu tinha meio que obrigação de, meio que seguir o caminho dele. De ir tão bem quanto ele... (Ricardo, 16 anos). ... a minha mãe era fumante, entendeu, com 14 anos... uma vez ela descobriu que eu tava fumando com 14 anos (risos) cigarro... no caso. Então ela veio e falou comigo: olha... tu tem.. ela chegou e abriu o jogo.. tu tem 14 anos, eu não queria ver um filho meu viciado. Eu fui e sei o quanto é ruim, e consegui parar.. mas, tu é o dono da tua vida e enfim né... mas não ia fazer sentido ela ter fumado desde sempre e depois dizer que eu não podia fumar (Vinícius, 17 anos).

A clássica premissa de que "as ações falam mais alto do que as palavras" parece ser verdadeira no que diz respeito às relações parentais. Gronhoj e Thogersen (2012), em pesquisa sobre a manutenção de comportamentos pró-ambientais, observam que a percepção das ações parentais tem mais impacto sobre os comportamentos dos filhos do que a descrição da norma em si; por isso a influência das regras depende da visibilidade e da não ambiguidade do comportamento parental.

\section{Manutenção das regras}

A partir do estabelecimento e negociação das regras os pais utilizam a cobrança, a punição e o controle para garantir sua manutenção. Os participantes acreditam que os pais se sintam responsáveis por eles, que queiram o melhor para eles, e por isso existem cobranças. Outros participantes afirmam que os pais cobram porque sabem que se não houvesse cobrança as metas impostas não seriam alcançadas pelos jovens:

E por que os pais cobram? [moderadora
do grupo] - Porque eles se sentem
responsáveis (Isabela, 15 anos). Por que
eles conhecem o filho que têm e sabem
que se não cobrar ninguém faz nada
(Lucas, 17 anos). Porque eles são
responsáveis por mim (Isabela, 15
anos). Porque eles querem o melhor pra
mim (Leticia, 16 anos). Porque não
querem pagar mais um ano de colégio
(Lucas, 17 anos).

Os participantes não concordam quando à necessidade de serem ou não cobrados. Alguns acham a cobrança boa ou necessária e outros não sentem que precisam ser cobrados para seguirem as expectativas parentais.

\begin{abstract}
$E$ isso é bom ou ruim, cobrança? [moderadora do grupo] - É bom (Leticia 16 anos). Às vezes é bom (Isabela, 15 anos). Durante é ruim... Mas às vezes precisa (Lucas, 17 anos). Eu sou uma pessoa que eu não funciono quando tem alguém me pressionando (Melissa, 18 anos). Eu, ao contrário, se tem alguém pressionando me dou muito melhor (Vanessa, 16 anos).
\end{abstract}

Por outro lado, alguns participantes acreditam que as cobranças nem sempre são justas:

Lá em casa é assim também, tipo... eu levei o lixo todo dia pra fora, durante cinco meses, aí um dia que tu esquece... (Fabrício, 16 anos) Sim, se tu não faz uma coisa, meu Deus do céu, né? (Isabela, 15 anos) Elas cobram como se tu não fizesse absolutamente nada 
(Leticia, 17 anos). Já eu que não faço nada, quando eu faço alguma coisa... aí é elogios... Então o negócio é não fazer nada... (todos riem) (Lucas, 17 anos).

A punição também é usada pelos pais para garantir a obediência às regras. A maioria das punições consiste na retirada de vantagens ou no cerceamento da liberdade dos jovens: "Na minha casa já aconteceu essa situação [de fazer algo que os pais não queriam e ser descoberta]. Eu fui punida (Melissa, 18 anos). Como? [moderadora do grupo] - Eu fiquei um bom tempo sem sair".

Em algumas famílias, a manutenção das regras é também estabelecida através do controle. Alguns adolescentes relatam que os pais controlam horários de saída e chegada em casa, onde podem ir e até mesmo que tipo de atividade podem participar:

Ah, algumas coisas é difícil de fazer. Eles controlam e não abrem mão. Tipo o que? [moderadora do grupo] - Ah, viajar com pessoas que eles não conhecem... (Vanessa, 16 anos). Bate e volta [viajar e voltar no mesmo dia] (Larissa, 16 anos). Em algumas épocas controlam o horário de voltar pra casa (Celia, 16 anos).

Alguns dos adolescentes acreditam que tal controle é necessário, enquanto outros o entendem como excessivo:

... se teus pais sempre deixam fazer tudo, tudo o que tu pedir tu vai lá e deixa, não coloca regra, não controla nada... Uma hora vai dar errado... Tu não vai sempre te sair ileso (Fabricio, 16 anos) controlar um pouco, né? ... mas não o tempo todo (Vinícius, 17 anos). Mas não trancar uma pessoa dentro de casa, né? Tem hora que eles exageram... (Fabricio, 16 anos).

Outros acreditam que seja possível (e até fácil) "enganar" o controle dos pais, já que estes não sabem de tudo que eles fazem, ou se estão mesmo seguindo as regras estipuladas:

[se não seguem as exigências dos pais] dá problema? [moderadora do grupo] Só eles não descobrirem... (Lucas, 17 anos). Mas eles [os pais] sempre dão um jeito de descobrir (Isabela, 15 anos). Não... (Lucas, 17 anos). É, não, tem várias coisas que minha mãe nunca descobriu... Várias coisas... (Vanessa, 16 anos).

Nesse embate entre a obediência às regras parentais e a autonomia, a resistência e o controle de informações surgem como forma de manutenção da confiança e relacionamento com os pais e construção de espaços de liberdade e autonomia. Além da negociação e argumentação, já discutidas anteriormente, os jovens se utilizam de estratégias menos habilidosas, como a transgressão escondida, a abertura parcial (contar apenas parte da verdade) ou a omissão (se não perguntarem eu não falo). Mesmo que aparentemente a intenção dos jovens seja a manutenção de um bom relacionamento com os pais, a necessidade de autonomia parece necessariamente levar a transgressões:

Mas é difícil quando as pessoas fazem alguma coisa errada e os pais ficam bravos elas não fazerem mais a coisa errada, sabe? Elas querem conquistar a confiança, mas elas continuam fazendo a coisa errada... não dá pra mudar muito. Então eu acho que continua fazendo as coisas, mas não deixa os pais saberem, entendeu? (Leticia, 16 anos).

Pesquisadores que estudam os processos de controle de informação afirmam que estratégias que envolvam engano (como a mentira) tem se demonstrado mais aversivas para o relacionamento parental do que aquelas que envolvem o segredo ou abertura parcial (Parkin \& Kuczynski, 2012). O uso dessas estratégias pode sinalizar a existência de incoerências entre pais e filhos no que se refere à autonomia dos adolescentes (ou os filhos desejam autonomia maior do que aquelas com as quais têm condições de lidar ou os pais não estão atentos às necessidades de autonomia de cada idade). Além disso, essas estratégias pouco habilidosas podem indicar dificuldades no relacionamento parental como falta de legitimidade da autoridade parental ou comunicação e suporte (Rote et al., 2012).

Os participantes, especialmente os mais velhos (17, 18 anos), afirmam que o controle parental tem limites, pois eles sabem o que é melhor pra si ou suas ações se realizam num risco calculado:

É, tem coisa que não tem como... proibir (Isabela). Mas os pais de vocês, às 
vezes, fazem as regras pra proteger vocês... e mesmo assim, não vale a pena obedecer? Não há risco? [moderadora do grupo] - Mas é porque... tu sabe, tu pode saber que é ruim, mas tu não tá pensando na coisa..., tá pensando na... em agora ...e agora eu tô a fim de fazer... (Celia, 16 anos). Eu acho que a questão é cada um, é... ninguém aqui é mais criança, entendeu? Cada um sabe o que é melhor pra si... Então se eu bebo e gosto e minha mãe diz pra eu não beber, o fato é que eu vou continuar bebendo, ela querendo ou não. $E$ não é se... se teu pai falar: tu vai na festa hoje mais tu não vai beber, se tu quer beber tu vai lá e tu vai beber (Vinícius, 17 anos).

Ao Ihes ser perguntado se o controle parental tem alguma influência, os participantes apontam as diferenças impostas pelos relacionamentos entre pais e filhos. Segundo eles, em relacionamentos mais próximos, de maior legitimidade parental, ou seja, em relacionamentos em que os filhos respeitam mais a imagem e autoridade dos pais, as orientações dos pais são levadas em conta como guia, e influenciam o comportamento dos jovens, o que é corroborado pela literatura científica (Rote et al., 2012; Stattin \& Kerr, 2000).

\begin{abstract}
O que o pai fala então não vai mudar seu comportamento? [moderadora do grupo] - Depende da pessoa... tipo, tem pessoas que o que os pais vão falar vai ser diferente porque vai influenciar o que a pessoa pensa que é certo ou não, o quanto ela valoriza a ideia dos pais. Tem outros que não vai fazer diferença... Ela não leva em conta o que o pai fala porque pode fazer o que quiser, não vai mudar nada... (Antônio, 16 anos).
\end{abstract}

Outro fator que pode influenciar $o$ comportamento dos jovens é a forma de ação dos pais. Segundo os participantes, punir, gritar, não ouvir os jovens são atitudes que dão menos resultados do que uma conversa franca:

Eu prefiro que meu pai chegue e me espanque do que ele venha com aquela conversa de ah... tô muito decepcionado contigo com isso que tu fez, eu não esperava isso de... bah, isso é pior que... meu Deus, um soco na boca (Vinícius, 17 anos). Sim, vai te fazer pensar muito mais (Isabela, 15 anos). É... eu acho que uma boa conversa, assim que faz tu pensar.. (Larissa, 17 anos) e do modo que é falado também... minha mãe quando ela se estressa ela começa a falar alto... aí eu não ouço mais nada... (Antônio, 16 anos). Eu nem converso com o meu pai porque ele grita, ele grita e aí não tem como... eu me irrito e mando todo mundo pra $p^{*} q^{*} p^{*}$ e me tranco no quarto (Juliana, 16 anos).

Essa conversa pode não mudar completamente o comportamento dos jovens, mas consegue resultados:

\begin{abstract}
Mas mesmo assim [com a conversa] nem sempre você vai parar de fazer aquilo (Lucas, 17 anos). Tá, mas pelo menos vai ser de outro jeito... tipo, comigo já aconteceu de eu chegar mal [bêbada] em casa e a minha mãe me dar sermão e tal... Ela vem e diz... "não é porque tu tá bebendo, mas por segurança, porque tu não sabe o que tá fazendo, podia ter chegado qualquer pessoa e ter feito uma coisa contigo". Sei lá, eu acho que não vou deixar de beber, mas eu tento não exagerar, entendeu? (Vanessa, 16 anos).
\end{abstract}

Pesquisadores já apontam a importância da conversa entre pais e filhos (Parkin \& Kuczynski, 2012). O uso dessa estratégia de negociação parece oferecer espaço para que os filhos apresentem seu ponto de vista e suas necessidades ao mesmo tempo em que os pais podem exercer a autoridade necessária para a saudável manutenção de regras e limites.

\section{CONSIDERAÇÕES FINAIS}

A construção das regras é feita a partir da prescrição dos pais e também pela negociação que se dá na interação pais e filhos, de acordo com a necessidade do contexto ou situação e o comportamento dos adolescentes. Sua manutenção é marcada pelo uso de estratégias por parte dos pais e também dos filhos. Os pais utilizam estratégias como a cobrança, punição e controle para garantir que as regras estabelecidas sejam cumpridas; os filhos, por sua vez, utilizam a resistência e o controle de informações para manter um bom relacionamento com os pais e ainda assim construir algum espaço para sua autonomia.

Transversalmente, os sujeitos investigados demonstraram ter consciência de como seus 
pais se comportam. Fica claro que eles realmente compreendem as expectativas parentais com relação às regras, ao mesmo tempo em que conseguem prever as reações de seus progenitores diante de sua obediência ou não ao estabelecido. Essa consciência pode permitir aos jovens certa elasticidade no processo obediência $x$ autonomia e, em algumas situações, o controle do processo de construção e manutenção das regras familiares. De forma geral, os filhos reportaram bastante liberdade no processo de obediência às regras. As perguntas que se originam dessa percepção dos dados são: os pais são realmente tão permissivos quanto é possível perceber através das falas dos filhos? A visão dos filhos sobre as práticas parentais é inadequada? Ou foi preciso os jovens mostrarem-se mais autônomos e independentes diante do grupo?

A literatura especializada apresenta explicações para todas essas hipóteses. Por um lado, pesquisas têm apontado a dificuldade atual de alguns pais em exercer sua autoridade. Muitos progenitores se sentem culpados pelo pouco tempo que podem dispensar aos filhos e por não oferecerem a eles o modelo idealizado de família (Stengel, 2011). A culpa e a falta de tempo têm dificultado a tarefa parental, especialmente no que tange à construção e manutenção das regras. Por outro lado, pesquisas demonstram que filhos percebem os pais muito menos exigentes e responsivos do que os pais dizem ser (Weber, Prado, Viezzer, \& Brandenburg, 2004), o que pode explicar a percepção de liberdade que os adolescentes reportaram sobre 0 relacionamento que estabelecem com seus pais. Por outro lado, outros estudos também demonstram que o desejo de autonomia expresso pelos jovens adolescentes é maior do que o que seus pais permitem (Rote \& Smetana, 2014), o que pode ter levado os participantes a reportarem a autonomia desejada, e não a real.

Além das intenções que tinham os participantes ao falarem sobre seu relacionamento familiar, pode-se afirmar que os dados encontrados corroboram os achados na literatura especializada sobre a forma de construção/existência das regras na família (Parkin \& Kuczynski, 2012), assim como as estratégias utilizadas por pais e filhos para mantê-las (Parkin \& Kuczynski, 2012; Rote et al., 2012). Conhecer tal funcionamento nos permite compreender quanto é importante que os pais se mantenham no exercício e responsabilidade de construir e manter as regras, mesmo em tempos de tanta flexibilidade. É patente o desejo dos jovens de participar ativamente desse processo, sentindo-se ouvidos e compreendidos, sem que esse desejo impeça o exercício da autoridade dos pais, função que pode e deve ser desempenhada sem exageros ou autoritarismo.

Com relação ao ponto de vista dos adolescentes, deve-se compreender que o desejo de autonomia e a necessidade de enfrentamento da autoridade constituem um processo normativo e saudável, e que criar num espaço de afeto, confiança, comunicação e regras claras tem como resultado o desenvolvimento saudável da autonomia. Dessa forma, é importante que pais e filhos tenham a flexibilidade de adequar suas exigências e adaptar a forma de comunicação para um novo momento do ciclo vital, de forma a manter as regras necessárias para 0 funcionamento saudável da família e, ao mesmo tempo, dar suporte para o desenvolvimento da autonomia do adolescente.

Finalmente, algumas limitações do presente estudo podem ser apresentadas. Sua construção metodológica qualitativa não permite uma avaliação se os dados aqui discutidos se referem também a outros grupos adolescentes. Outra dificuldade se refere ao fato de o estudo analisar uma relação bidirecional - pais e filhos - apenas do ponto de vista dos adolescentes. Conhecer a visão dos pais sobre a construção e manutenção das regras familiares através de um grupo focal com os responsáveis poderá apresentar uma visão mais completa e sistêmica de como esse fenômeno se configura na família, mas aqui apenas se buscou apresentar pistas de como essa construção se dá, de forma a subsidiar ações junto às famílias, assim como embasar outras pesquisas sobre uma temática ainda pouco discutida no Brasil.

\section{REFERÊNCIAS}

Bardin, L. (2002). Análise de conteúdo. Lisboa: Edições 70.

Carter, B., McGoldrick, M. (1995). As mudanças no ciclo de vida familiar: Uma estrutura para a terapia familiar. Porto Alegre: Artes Médicas.

Cumsille, P., Darling, N., \& Martínez, M. L. (2010). Shading the truth: The patterning of adolescents' decisions to avoid issues, disclose, or lie to parents. Journal of Adolescence, 33, 285-296. 
Darling, N., Cumsille, P., Caldwell, L. L., \& Dowdy, B. (2006). Predictors of adolescents' disclosure to parents and perceived parental knowledge: Between- and withinperson differences. Journal of Youth and Adolescence, 35, 667-678.

Flannery, D. J., Vazsonyi, A. T., Torquati, J., \& Fridrich, A. (1994). Ethnic and gender differences in risk for early adolescent substance use. Journal of Youth and Adolescence, 23, 195-213.

Gronhoj, A., \& Thogersen, J. (2012). "Action speaks louder than words": The effect of personal attitudes and family norms on adolescents' pro-environment behavior. Journal of Economic Psychology, 33, 292-302.

Keijsers, L., \& Laird, R. D. (2010). Introduction to special issue. Careful conversations: Adolescents managing their parents' access to information. Journal of Adolescence, 33, 255-259.

Kerr, M., Stattin, H., \& Burk, W. J. (2010). A reinterpretation of parental monitoring in longitudinal perspective. Journal of Research on Adolescence, 20(1), 39-64.

Laird, R. D., \& Marrero, M. D. (2010). Information management and behavior problems: Is concealing misbehavior necessarily a sign of trouble? Journal of Adolescence, 33, 297-308.

Livingstone, S. (2007). Strategies of parental regulation in the media-rich home. Computers in human behavior, 23, 920941.

Maccoby, E. (2007). Historical overview of socialization research and theory. In J. Grusec \& P. Hastings (Eds.). Handbook of Socialization Research (pp. 13-41). New York, NY: Guildford.

Millward, L. J. (2006). Grupos focais. In. G. Breakwell, S. Hammond, C. Fife-Schaw, \& J. A. Smith. Métodos de pesquisa em psicologia. Porto Alegre: Artmed.

Parkin, C. M., \& Kuczynski, L. (2012). Adolescent perspectives on rules and resistance within the parent-child relationship. Journal of Adolescent Research, 27(5), 632-658.

Rodrigo, M.J. \& Palacios, J. (Coords.) (2003) Familia y desarrollo humano. Madri: Alianza Editorial.

Romanelli, G. (2000). Autoridade e poder na família. In. M. do C. B. Carvalho (2000). A familia contemporânea em debate (pp. 73-88). 3. ed. São Paulo: Cortez.

Rote, W. M., \& Smetana, J. G. (2014). Acceptability of information management strategies: Adolescents' and parents' judgments and links with adjustment and relationships. Journal of Research on Adolescence. doi: 10.1111/jora.12143.
Rote, W. M., Smetana, J. G., Campione-Barr, N., Villalobos, M., \& Tasopoulos-Chan, M. (2012). Associations between observed mother-adolescent interactions and adolescent information management. Journal of Research on Adolescence, 22(2), 206-214.

Sampson, R. J., \& Laub, J. H. (1994). Urban poverty and the family context of delinquency: A new look at structure and process in a classic study - Children and poverty [Special issue]. Child Development, 65, 523-540.

Smetana, J. G. (1997). Parenting and the development of social knowledge reconceptualized. In J. E. Grusec \& L. Kuczynski (Eds.), Parenting and the internalization of values: A handbook of contemporary theory (pp. 227-256). New York: Wiley.

Smetana, J. G., Villalobos, M., Tasopoulos-Chan, M., Gettman, D. C., \& Campione-Barr, N. (2009). Early and middle adolescents' disclosure to parents about activities in different domains. Journal of Adolescence, 32, 693-713.

Stattin, H., \& Kerr, M. (2000). Parental monitoring: a reinterpretation. Child Development, 71(4), 1072-1085.

Stengel, M. (2011). O exercício da autoridade em famílias com filhos adolescentes. Psicologia em Revista, 17(3), 502521.

Wagner, A., Mosman, C. P., Dell'Aglio, D. D., \& Falke, D. (2010). Família \& Internet. São Leopoldo: Sinodal.

Wagner, A., Predebon, J., Mosman, C., \& Verza, F. (2005). Compartilhar tarefas? Papéis e funções de pai e mãe na família contemporânea. Psicologia: Teoria e Pesquisa, 21(2), 181-186.

Weber, L. N. D., Prado, P. M., Viezzer, A. P., \& Brandenburg, O. J. (2004). Identificação de Estilos Parentais: O ponto de vista dos pais e dos filhos. Psicologia: Reflexão e Crítica. 17(3), 323-331.

White, M. J., \& Kaufman, G. (1997). Language usage, social capital, and school completion among immigrants and native-born ethnic groups. Social Science Quarterly, 78, 385-398.

Recebido em 03/10/2013 Aceito em 30/06/2014

Paola Vargas Barbosa: doutoranda em Psicologia pela Universidade Federal do Rio Grande do Sul, Brasil.

Adriana Wagner: professora do Departamento de Psicologia da Universidade Federal do Rio Grande do Sul, Brasil. 